\title{
Potential benefits of ICT towards rural positive youth development in Malaysia
}

\begin{abstract}
Information Communication Technology (ICT) offers an abundance of benefits to users especially in socio-economic aspects. Rural youth are one group of users that has experienced such benefits. They are able to access more opportunities due to their superior ICT knowledge and compatibility. This study aims to identify the potential benefits of ICT usage for rural youth development. Through document analyses and review of literature, it can be concluded that the benefits offered from ICT usage towards youth development can be categorized in the aspects of competency, character, confidence, caring, connection and contribution. With all of these aspects of potential benefits in place, it is hoped that consistent involvement from youths in rural development can be ensured.
\end{abstract}

Keyword: Information communication technology; Youth in Malaysia; Rural youth; Positive youth development; Rural development 